Síntesis

En el marco de las celebraciones que en el ámbito universal tienen como objetivo conmemorar los cuatrocientos años de la primera parte de la obra de Miguel de Cervantes Saavedra, publicada a comienzos de 1605 con el título de El ingenioso hidalgo don Quijote de la Mancha, se incluye

este artículo que refleja el interés que el Departamento de Lenguaje y Comunicación y la Facultad de Ciencias de la Comunicación de Uniminuto sienten por la lengua española y por su literatura como la expresión de la identidad hispanohablante manifiesta en los procesos culturales mediante los cuales la sociedad, en particular aquella de quienes luchan por la reivindicación de los espacios en los cuales legítimamente deben escucharse, comprenderse e interpretarse las voces que, dialógicamente, representan con justicia el mundo de los hechos humanos.

Synthesis:

In the frame of the celebrations that they aim at the universal space commemorating the four hundred years of Cervantes Saavedra's first part of Miguel's work, published at the beginning of 1605 under the title of The ingenious nobleman Mr. Quixote of the stain, this article includes itself

that you reflect the interest that Lenguaje's and Comunicación's Apartment

and Ciencias's Faculty of Uniminuto's

Communication establish for the

Spanish tongue and for his literature like the expression of the

Spanish-speaking manifest identity in the cultural intervening processes

which the society, in particular that one whose they fight for the

redemption ofThe spaces which legitimately they must listen in,

understanding and interpreting the voices than, dialógica, they represent the world of the human facts with justice.

\section{Lenguajes 400 años de don Quijote y Sancho}

\section{María C. Asqueta Corbellini}

masqueta@yahoo.es

Docente - investigadora, directora del departamento de Lenguaje y Comunicación. Coordinadora del Área de Lenguajes del programa de Comunicación Social- Periodismo de UNIMINUTO.

(...) mi lectura del Quijote me mereció siempre un capítulo aparte, porque no me causó la conmoción prevista por el maestro Casalins. Me aburrían las peroratas sabias del caballero andante y no me hacían la menor gracia las burradas del escudero, hasta el extremo de pensar

que no era el mismo libro de que tanto se hablaba. Sin embargo, me dije que un maestro tan sabio como el nuestro no podía equivocarse, y me esforcé a tragármelo como un purgante a cucharadas. Hice otras

tentativas en el bachillerato, donde tuve que estudiarlo como tarea

obligatoria, y lo aborrecí sin remedio, hasta que un amigo me aconsejó que lo pusiera en la repisa del inodoro y tratara de leerlo mientras cumplía con mis deberes cotidianos. Sólo así lo descubrí, como una deflagración, y lo gocé al derecho y al revés hasta recitar de memoria episodios enteros.

GABRIEL GARCÍA MÁRQUEZ, Vivir para contarla 


\section{Miguel de Cervantes Saavedra' ${ }^{1}$, para suerte}

y desdicha suya, fue un hombre de dos siglos; del XVI que lo vio nacer, en el que se iniciaron sus desventuras; y del siglo XVII, cuando consiguió ser escritor de cierto renombre, aunque de éxito esquivo.

El conocimiento que se tiene de la época que le tocó vivir y de cómo vivió es un asunto que inició con la investigación de los archivos, públicos y privados en el siglo XVIII la cual ha sido proseguida ininterrumpidamente hasta nuestros días, cuando son numerosísimos sus biógrafos, comentaristas, lectores y admiradores.

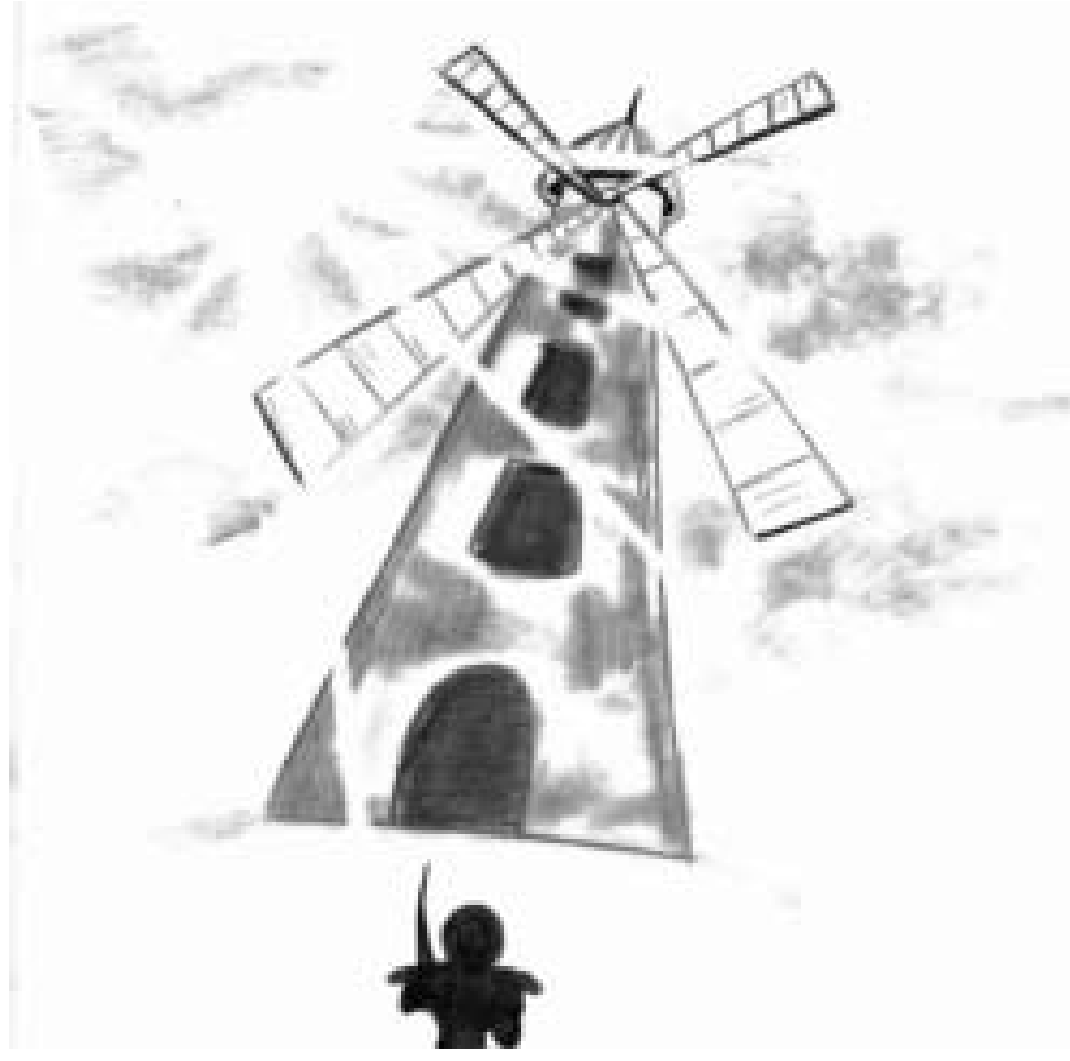

En consecuencia, cuánto más se conoce más inferencias surgen, de modo tal que obra y contexto constituyen un campo amplio y prolífico para la investigación y el análisis; en tanto, toda la información permanece en una continua revisión.

$\overline{{ }^{1} \text { Miguel de Cervantes Saavedra nació el } 29 \text { de septiembre de } 1547 \text { en }}$ Alcalá de Henares (Madrid-España). Fue el cuarto de los cinco hijos del cirujano Rodrigo de Cervantes y de Leonor de Cortinas. A sus 4 años la familia se trasladó a Valladolid, ciudad donde residía la corte del rey de España, Felipe II. En 1561 la corte fue llevada a Madrid y la familia Cervantes se traslada también. Asistió a un colegio de jesuitas pero se ignora la ciudad, se supone que fue Valladolid. En Madrid, fue alumno de Juan López de Hoyos, literato de la época. Recorrió Italia, se enroló en la Armada Española y en 1571 combatió con heroísmo en la batalla de Lepanto, "la más grande ocasión que vieron los siglos". En la contienda, formaban el frente cristiano: la marina española, el estado del Vaticano y el estado de Venecia. Allí Cervantes recibió un disparo de arcabuz en el brazo izquierdo, por lo que fue llamado el Manco de Lepanto. El 26 de septiembre de 1575, de regreso a España, los corsarios asaltaron su barco en la desembocadura del río Ródano, le apresaron y llevaron a Argel, donde sufrió cinco años de cautiverio. Quedó libre después de que unos frailes trinitarios pagaran un rescate, el 19 de septiembre de 1580. A su regreso a Madrid encontró a su familia en la ruina. A los 37 años de edad se casó en Esquivias (Toledo) con Catalina de Salazar y Palacios, de 19 años; y, como su carrera militar ya estaba arruinada inició una carrera en las letras. Sin medios para vivir fue destinado a Andalucía como comisario de abastos y recaudador de impuestos para la Armada Invencible. Acabó en la cárcel, acusado de irregularidades en sus cuentas. También, fue excomulgado tres veces ante el intento de cobrar a la iglesia los impuestos que ésta estaba obligada a satisfacer. En 1605, evento que se celebra este 2005, publicó la primera parte del Quijote. El triunfo literario no lo libró de sus penurias económicas y, en 1606 regresó a Madrid, donde vivió con modestia dedicado a la producción literaria. Allí, murió el 23 de abril de 1616 y fue enterrado por una obra de caridad.

${ }^{2}$ Con este neologismo de Mario Vargas Llosa hago 
Cervantes ha sido estudiado, hasta donde sé, por su tocayo Miguel de Unamuno -a quien sin pelos en la lengua el escritor mexicano Fernando del Paso acusa de envidioso- que desconfiado de las cualidades literarias de su antecesor lo critica pero no desde una crítica disciplinar sino como el punto de vista de aquel que sospecha la falta de virtudes del otro texto, y de la cabeza y la mano que empuñaron el stylo.

Por su parte, Cervantes con adarga prestada -por Don Quijote- ha contraatacado porfiadamente. Así, tuvo cada vez menos detractores y más adeptos, como Américo Castro y Fernando del Paso, a quien acabo de citar. En Colombia, los adoraba -también a SanchoDon Ramón de Zubiría y, en estos días, la celebración de los 400 años que se está llevando a cabo hizo emerger una legión de especialistas en marchas manchegas que han creado un amplio campo de conocimientos sobre el autor y su obra.

De este modo, entre los eventos que han sido relacionados con la vida y la producción de Cervantes está, sin duda, su origen y no se trata del desconocimiento de los datos, parte de ellos consignados sucintamente en la nota al pie de la página, sino que en el siglo XVI de quien se tuviera sospechas sobre ancestros moros o judíos estaba condenado a vivir sin honor, hecho que en términos contemporáneos significa marginalidad social. Posiblemente, esta situación haya determinado que su vida estuviera pautada por búsquedas destinadas a superar la estigmatización.

Así, se sucedieron varios acontecimientos decisivos para su existencia; uno de ellos la cárcel entre los árabes después del desventajoso combate en Lepanto; los datos indican que en primer lugar quiso destacar como soldado; no le fue bien y logró emerger penosamente con la ayuda de quienes pagaron su rescate; de vuel-

\section{Lenguajes}

ta en España tuvo que trabajar como recaudador de impuestos, digno oficio que lo conduce directamente a la cárcel; estos eventos se suceden en vísperas de la publicación de la primera parte del Quijote.

Como correlato, en su obra, se encuentran diferentes referencias a la cultura mora en España. La existencia, en la novela de Cervantes, del escritor y traductor árabe de El Quijote acerca un texto en la cual permanentemente se hallan indicios para la comprensión de un contexto en el cual los expulsados aún hacen presencia y cuya situación debió dar lugar a diferentes corrientes de opinión que se diluyeron sin alcanzar a trascender para la posterioridad; aunque, éstas pueden ser inferidas a partir de la lectura minuciosa de las diferentes obras que testimonian el pensamiento y los puntos de vista de la época.

\section{Primera publicación: El ingenioso hidalgo don Quijote de la Mancha}

Por tanto, ¿a qué se dedicaría un veterano de guerra y ex recaudador de impuestos, en un tiempo en el cual proliferaban los escribidores ${ }^{2}$ ?, ¿qué más se le ocurriría, que competir con ellos, a quien se le reconoce la más grande creatividad del XVI y el XVII juntos y de los tiempos venideros? ${ }^{3}$ Así, probablemente con la misma pasión y deseo de ser representados por su personaje, literalmente lo parirá en esos años de más necesidades que potaies, para calmar el hambre v las angustias que

referencia a los autores de las novelas de caballería y pastoriles, como Diana de Jorge Sotomayor, leídas por Don Quijote y que le sorbieron el seso pero le dieron un corazón ilusionado propenso al amor.

${ }^{3}$ Cervantes se interesó por la poesía y el teatro. Su obra poética incluye sonetos, canciones, églogas, romances, letrillas y otros poemas menores dispersos o incluidos en sus comedias y en sus novelas; escribió dos poemas mayores: Canto de Calíope (incluido en La Galatea) y Viaje del Parnaso. Su poesía se ha visto perjudicada por ir incluida dentro de casi todas sus novelas por lo cual Cervantes no llegó a ser reconocido como 
siempre han caracterizado la vida de los pobres.

Martín de Riquer ${ }^{4}$ dice sobre la primera publicación de El ingenioso hidalgo Don Quijote de la Mancha que la más antigua de las versiones conocidas fue impresa

poeta, como le sucedió a William Shakespeare. Al regreso del cautiverio estrenó varias comedias, pero, sus contemporáneos no lo aceptaron como dramaturgo y tuvo que soportar el éxito de Lope de Vega en la escena española. De la primera época (1580-1587) se conservan dos tragedias: El trato de Argel y La destrucción de Numancia. A la segunda época pertenecen las Ocho comedias y ocho entremeses (1615). Las comedias son El gallardo español; La casa de los celos y selvas de Ardenia; Los baños de Argel; El rufián dichoso; La gran Sultana doña Catalina de Oviedo; El laberinto de amor; La entretenida y Pedro de Urdemalas. Y. los entremeses: El juez de los divorcios; El rufián viudo; La elección de los alcaldes de Daganzo; La guarda cuidadosa; El vizcaíno fingido; El retablo de las maravillas; La cueva de Salamanca; El viejo celoso. En sus últimos años publicó las Novelas ejemplares (1613), el Viaje del Parnaso (1614), Ocho comedias y ocho entremeses (1615) y la segunda parte del Quijote (1615). Dedicó sus últimos meses de vida a Los trabajos de Persiles y Segismunda (de publicación póstuma, en 1617). En la narrativa escribió una novela pastoril que fue su primer libro publicado, con el título de Primera parte de La Galatea (1585). Entre 1590 y 1612, se dedicó a las novelas cortas que, después del reconocimiento obtenido con la primera parte del Quijote, reunió en 1613 en la colección de Novelas ejemplares, obra que según sus admiradores le habría significado un lugar en la historia de la literatura. Se cuenta que Cervantes habría empezado a escribir el Quijote en alguno de sus periodos de encarcelamiento a finales del siglo XVI. En el verano de 1604 estaba terminada la edición de la primera parte, publicada a comienzos de 1605 con el título de El ingenioso hidalgo don Quijote de la Mancha; en el año 1614 apareció la publicación apócrifa escrita por Alonso Fernández de Avellaneda, quien acumuló en el prólogo insultos contra Cervantes. Los biógrafos señalan a su eterno rival y enemigo Lope de Vega, como la persona oculta tras el seudónimo. Cervantes acuciado por el robo literario hubo de darse prisa para la publicación de El ingenioso caballero don Quijote de la Mancha, en 1615; a partir del capítulo LIX, no perdió ocasión de ridiculizar al falso Quijote y de asegurar la autenticidad de don Quijote y Sancho. En 1617 las dos partes se publicaron juntas en Barcelona.

${ }^{4}$ DE RIQUER, Martín, Aproximación al Quijote, Madrid, Salvat, 1970, pág. 41.

${ }^{5}$ LARA ZABALA, Hernán, "El capítulo milagroso" en: Lecturas Dominicales, El Tiempo, sábado 23 de abril de 2005.

${ }^{6}$ JITRIK, Noé, "Cuatro siglos de fascinación" en: Lectura Dominicales, en Madrid por Juan de la Cuesta en 1605 y aunque se ha supuesto la existencia de una de 1604, de ella no existen evidencias. De tal manera, el personaje inició su idílica andanza en esa mitad de la primera década del siglo XVl; de esta manera quedaron previstos los potenciales lectores para seguir la aventura.

\section{Lanza en ristre contra los entuertos}

En cuanto a los múltiples lectores cuya curiosidad los lleva a regodearse página a página está el crítico Hernán Lara Zabala a quien le interesa en particular el capítulo VIII cuando Don Quijote acompañado de Sancho como testigo presencial de sus "espantables" aventuras, se enfrenta a los molinos de viento, escena que fungirá como imagen imperecedera de lo que se ha dado en llamar el quijotismo (... $)^{5}$. Por su parte, Noé Jitrik parafrasea al doctor Pedro Recio "de eso no ha de comer vuesa merced" porque en ese episodio encuentra una finura de alma que ordenaba una escritura sin descanso ${ }^{\circ}$. Como ellos, otros estudiosos han confesado en estas efemérides su fascinación por la obra y explicado el porqué.

En particular, me atrae poderosamente el objetivo de desfacer entuertos ${ }^{7}$ cosa que se hace por partida doble, en la realidad Alonso Quijano y en la ficción el caballero enajenado, no sólo en algún episodio o capítulo sino por todo el texto. En la realidad porque Cervantes tenía que soportar la suerte de los no privilegiados sometido a vejaciones e injusticias según se indica en

El Tiempo, sábado 23 de abril de 2005.

${ }^{7}$ En el Diccionario de la Real Academia de la Lengua Española, DRAE, el lema desfacedor de entuertos. se define como: (1. m. irón. coloq.) deshacedor de agravios.

${ }^{8}$ BARRIGA CASALINI, Guillermo, Los dos mundos del Quijote. Realidad y ficción, Madrid, Porrúa, 1983, pág. 34.

${ }_{9}$ Riquer escribe que Cervantes ha fingido (...) ser una especie de 
su biografía (ver nota 1 al pie de página) y en la ficción porque Don Quijote los hallaría en todas partes, sin buscar demasiado, esparcidos por toda la comarca manchega.

La expresión desfacer entuertos adquiere el significado de correr el velo que oculta la apariencia de realidad ante ciertos hechos; o es que acaso ino son gigantes los molinos de viento? Ante la duda, su dimensionalidad en medio de la llanura manchega connota algo enorme y amenazante; y aún más, esta imagen hace posible suponer que a pesar de su majestuosidad y

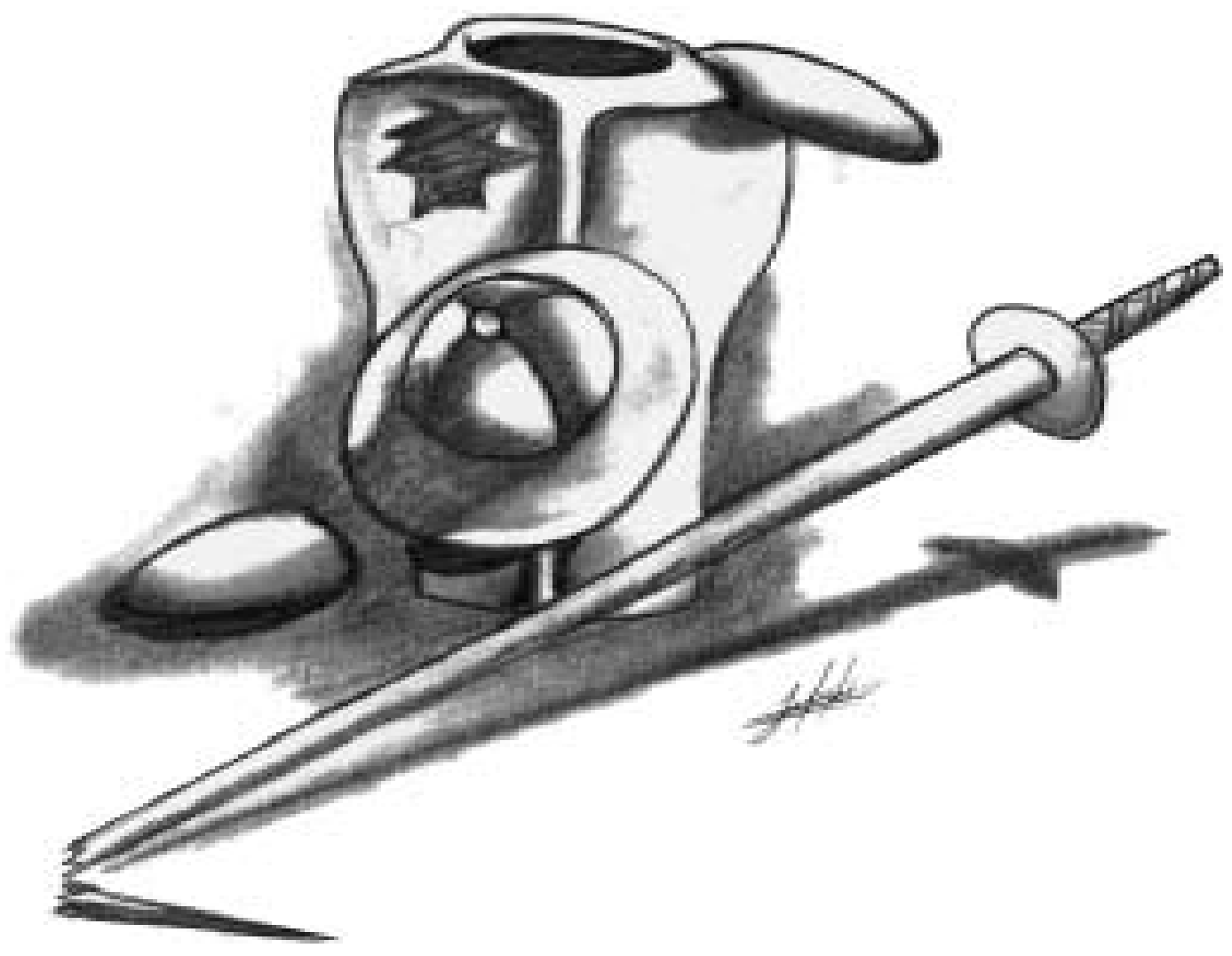
altura la molienda de

de los tiempos modernos ${ }^{8}$ que le aportan al terruño trigo no proveía raciones equitativas entre los españolitos de aquel tiempo. Su presencia frente a los ímpetus justicieros de Don Quijote obligaba a quitar la mala simiente de sobre la faz de la tierra con la derrota de esos desaforados gigantes. Más allá de la advertencia del aterrizado Sancho, que aquellos que allí se parecen no son gigantes, sino molinos de viento, estos de todas formas representan la amenaza del advenimiento

erudito que recopilaba datos de otros autores y de los papeles de los archivos de la Mancha para ordenar la historia de Don Quijote. Al emmanchego máquinas de moler para el aumento de la producción destinada a favorecer las arcas del poder sin que alcancen para llenar el estómago de los pobres. Frente a esta realidad la humanidad siempre parece vulnerable, pequeña, desprotegida y derrotada, como le sucedió al idealismo en esta confrontación.

Otras connotaciones, a la luz de la lectura contextual, tienen que ver con aquello que socialmente olía mal en algún lugar de la Mancha como, por ejemplo, en el episodio de la bestial golpiza con que se le paga 
el salario a un niño trabajador de la cual fue testigo el aventurero protagonista y que los lectores conocemos por la polifonía textual cervantina; de modo que en el suceso hablan tanto el castigado, como el castigador y el propio Don Quijote para dejar clara la magnitud de la ignominia. Este hecho tiene lugar en el capítulo cuatro de la primera parte, cuando Don Quijote regresa de su primera salida muy orondo y circunspecto, después de ser armado caballero y completamente listo para hacer justicia.

Respecto del significado documentado de la locución cervantina desfacer entuertos, la consulta al Diccionario de la Real Academia de la Lengua Española, indica que consiste en desfacer agravios. Entonces, resulta posible conectar el concepto lingüístico con la clase de ofensas sufridas por alguien dos veces preso, tres veces excolmugado y siempre pobre.

Por otra parte, el problema del poder de los menos está no sólo en la acumulación de bienes que no se comparten con los demás sino también en la soberbia que los lleva al menosprecio de algo que para ellos es vergonzante y en su conciencia ilegítimo; de ahí que los duques de la historia cervantina, en el capítulo treinta, son de verdad la mala gente y que para ellos la burla es el instrumento del vilipendio del otro y un claro mecanismo de exclusión. En cualquier caso, en-tuerto connota también algo torcido y oscuro; des-hacerlos constituye el motivo que lanza al inspirado Alonso Quijano al mundo, vivido por Don Quijote como el territorio enemigo puesto que aunque él lo mira con los mejores ojos encuentra siempre gentes dispuestas para la disputa, la riña y el escarnio.

Frente a ello, la dignidad de la pobreza del hidalgo apreciado por los vecinos no está contemplada por los poderosos como un valor social y mucho menos que se lance por los caminos con espíritu justiciero. Tal desigualdad constituye de veras un entuerto, como el agravio de aquello que esencial para el hombre: la humanidad. En este sentido el texto se abre a la interpretación de un humanismo iluminado que nos llega en la imaginación y la mano del autor, como una utopía esplendorosa; de igual modo, ética y estética del lenguaje. En ese sentido la obra no es sólo novela es una lección magistral, cosa ya muchos estudiosos han comprendido y escrito.

Así, el destino del caballero de la triste figura fue fungir como paladín de la justicia por una tierra en la cual campeaba lo contrario: demasiada pobreza para muchos, ventajas para algunos y los demás corrompidos por la necesidad de coger su tajada. La situación hizo que la avaricia y el hambre transitaran por allí cogidos del brazo regando entuertos.

La descripción barroca y realista que nos regala el autor es, desde mi lectura, la razón de ser del texto y la que verdaderamente lo condujo hacia la posterioridad, la cual se constituye en la reivindicación del hidalgo poco favorecido y de su homólogo, en cuanto a bienes y bienestar, el escritor. Para el punto de vista de Latinoamérica, tierra de oportunidades que le fueran negadas a Cervantes, este paradigma del hidalgo pobre está en la raíz misma del contingente migratorio español que nos mestizó, ¿quiénes sino ellos, pobres segundones abandonados por su sociedad, encontraron en estas latitudes alimentación y amparo?

Del mismo modo, ¿qué mejor manera halló Cervantes para representar la realidad que desde el punto de vista de un personaje literario? La locura del Quijote no es patológica pero sí prolífica en representaciones y ficciones; si la letra magnifica ello es necesario porque un racionalista, en su tiempo y en todos los tiempos, 
contradictoriamente está inhibido para percibir los dobleces de la realidad. De mil maneras ha sido leído El Quijote pero, me parece, faltó la lectura filosófica. Rafael Maya, en su discurso ante la Academia Colombiana de la Lengua en conmemoración del cuarto centenario del nacimiento de Cervantes, titulado Los tres mundos del Quijote dice: (...) La acción, muchas veces, es el pensamiento realizado y el sueño que toma forma sensible; en el sueño, en la ficción, en la poesía suele haber potencialmente vigorosos principios de acción; el pensamiento y la filosofía son en parte acción y en parte sueño (...) La filosofía se le convierte en acción, como acontece en el discurso de las armas y las letras. A pesar de sus esfuerzos, Miguel de Unamuno frente al texto sólo pudo actuar como filólogo para preguntar y responderse sobre las cualidades de la pluma cervantina.

Sin embargo, nada en este texto tan amplio y complejo debe dejarse de leer así como tampoco debe obviarse el contexto del siglo XVI para tomar en cuenta que en el origen mismo del pensamiento racionalista, el raciocinio de Cervantes le hace decir al de la teja corrida que la razón con la sinrazón se hace, frase sin parangón aunque de cierta analogía con: Pienso, luego existo.

La aparente normalidad de la vida cotidiana, es innegable, encierra entuertos y sólo el ojo avizor orientado por la imaginación posee el filtro y el lente adecuados para descubrirlos. Esta es función textual del Quijote, desenmascarar la realidad oculta para que destaque ante la mirada. De tal modo se escribieron los múltiples hechos, las salidas aventureras de Don Quijote, surgidas de los papeles desperdigados que habían sido escritos por un moro y reunidos por el propio Cervantes, los cuales constituyen intertextos que conforman la primera edición y las restantes de El ingenioso hidalgo Don Quijote de la Mancha.

\section{Lenguajes}

De ahí que, los dos aspectos más importantes a considerar en la escritura cervantina están la referencialidad $y$, sin dudarlo, la poética alcanzada por su escritura esencialmente metafórica. ¿Cómo habría podido el leal súbdito de la monarquía de Felipe II, de quien como los demás felipes ya se sabe la fama con la que pasaron a la historia, narrarnos la realidad sin acabar en las mazmorras? Lo hizo, de igual manera que su contemporáneo Diego de Velásquez en Las Meninas, ocultando sus textos en los pliegues de otros textos. La metodología se conoce como intertextualidad; de este modo Cervantes no se manifiesta en la obra como el autor y delega sus poderes en otros narradores como Cide Hamete Benengeli ${ }^{9}$. El escritor mexicano Carlos Fuentes en su discurso de aceptación del doctorado honoris causa de la Universidad de Castilla-La Mancha, el 20 de abril de 2005 pregunta: ¿Quién escribe la novela que leemos? ¿Un tal Cervantes, más versado en desdichas que en versos, cuya Galatea ha leído el cura que hace el escrutinio de los libros de don Quijote? ¿Un tal de Saavedra, mencionado por el Cautivo con admiración, a causa de los hechos que cumplió para alcanzar su libertad? ¿O se debe la autoría al agónico quehacer del historiador arábigo y manchego Cide Hamete Benengeli, quien vierte al castellano los papeles

pezar el capítulo 9 el mismo Cervantes se introduce en las páginas de su novela, apesadumbrado por no saber más de Don Quijote, cuyos hechos cree que debieron ocurrir en tiempos (...) Explica Cervantes que encontrándose un día en Toledo tuvo oportunidad de hacerse de unos cartapacios y papeles viejos escritos en árabe y que gracias a un morisco se enteró de que se trataba de una obra llamada "Historia de don Quijote de la Mancha, escrita por Cide Hamete Benengeli, historiador arábigo" (...) Cervantes hará ver que se permite hacer algún comentario, y algunas veces se llamará a si mismo "traductor".

${ }^{10}$ FUENTES, Carlos, "Elogio de la incertidumbre" en: Lecturas Dominicales, El Tiempo, 7 de mayo de 2005.

${ }^{11} \mathrm{Me}$ apropio de este concepto sobre la dialéctica en el ensayo de Roland Barthes, La retórica antigua. 
de un anónimo traductor morisco: un relato rescatado, casi, del basurero? ¿O será verdadero autor del Quijote el villano usurpador Alonso Fernández de Avellaneda, autor de la versión apócrifa que se convierte en parte de la segunda parte de la novela cuando obliga a Don Quijote a cambiar de ruta y seguir a Barcelona a fin de denunciar la farsa de Avellaneda y demostrar que él, "don Quijote, es el verdadero personaje real del Quijote"? (...) $)^{10}$

Este Cide Hamete Benengeli, autor y personaje, con su presencia en la obra rememora y referencia, a la cultura árabe, como expongo en un párrafo anterior, expulsada de España pero sin que se fuera jamás del todo.

\section{Don Quijote y Sancho}

Los personajes Don Quijote y Sancho, han hecho que el mundo sea otro con ellos. Pobre el caballero y pobre el escudero, ambos supieron identificarse tan bien que cerraron filas alrededor del interés materialista sobre la gobernación de ínsulas, tan necesaria para aliviar las desdichas de la miseria. La compenetración de los dos resulta casi en una dialéctica erotizada ${ }^{11}$ a la manera platónica, porque, al menos Sancho idolatra al amo que le da un trato humano en tiempos en los cuales, es posible inferir, escaseaba haciendo de él otra de las víctimas del entuerto.

La amistad de ambos sólo puede producir envidia; la fidelidad de Sancho carece del envilecimiento hipócrita del vasallo y su amo puede compartir sinceramente con él su comida y su jumento; además, existe la certeza de que los premios que él obtenga en sus batallas tienen al escudero como legítimo dueño.

Las audiencias contemporáneas, aún sin haber leído al Quijote, se conmueven con las versiones del cine y

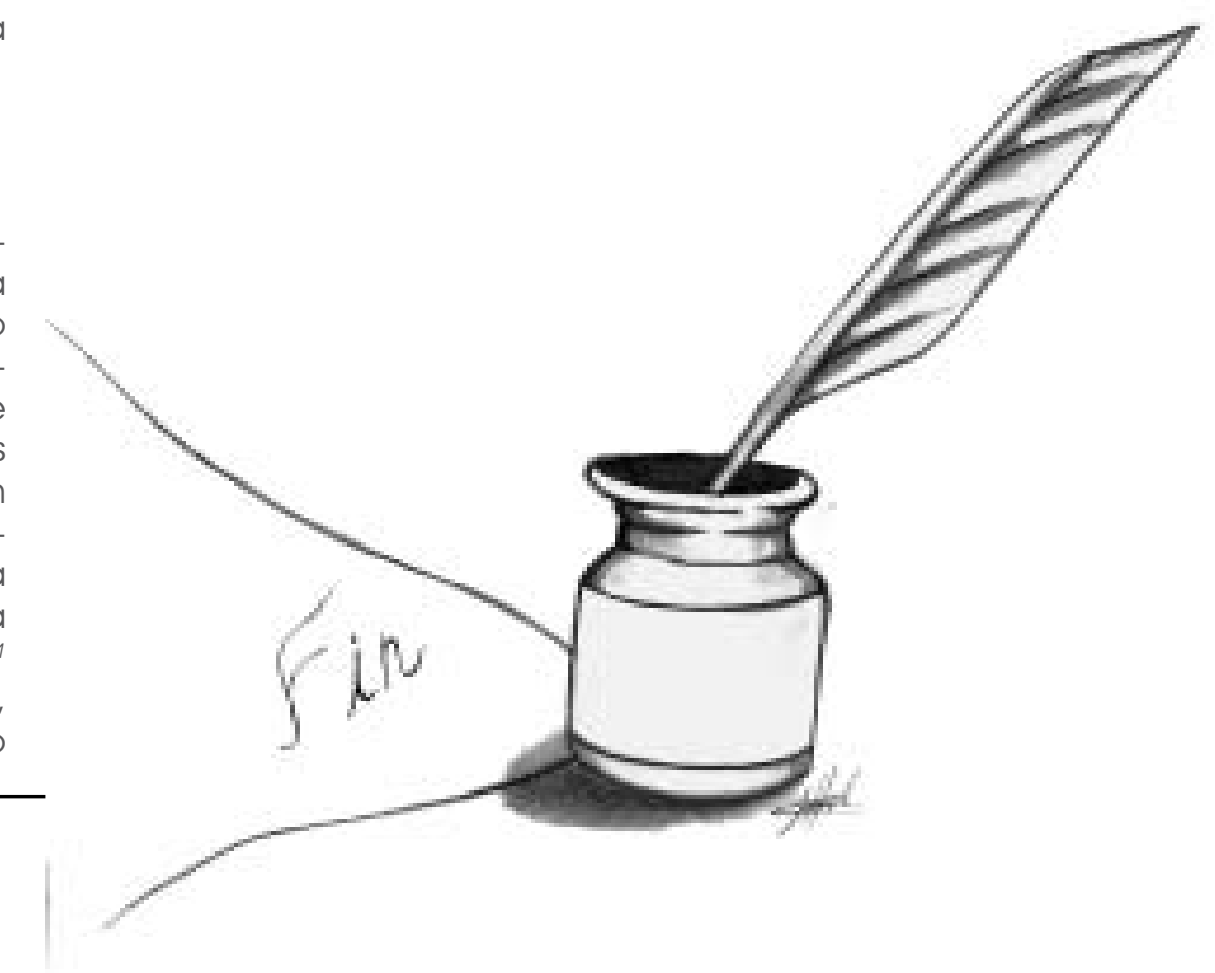


del comic, palimpsestos que ponen en contacto al del jumento y al del pollino con los nuevos receptores, en quienes encuentran más admiración y reconocimiento, en gran parte debido a la fuerte identidad lograda entre ambos.

Reiteradamente, se ha insistido sobre el carácter fantasioso del caballero de la triste figura y sobre el realismo de Sancho. Pero, Don Quijote tiene que resarcirse de la mediocridad que caracterizaba la vida de Alonso Quijano, con ausencia de emociones y solitaria y, por su parte, Sancho debe recompensar su concreta humanidad por la falta de algo que llevar a su boca y, lo que es más importante, de la de su familia; detrás de su aspiración a la gobernación está su temible Teresa que no está interesada para nada en el aventurero ocio manchego; sin embargo, tampoco ella podrá escapar a la fascinación y de esta manera ambos esposos son deslumbrados por la prolífica imaginación del caballero y aspiran al premio mayor: la ínsula Barataria.

Por este camino, detrás de la pareja protagónica, de Don Quijote y Sancho, asoman otras, como la mencionada de Sancho y Teresa Panza. Por supuesto, el Quijote enamorado reclamará en toda aventura, como premio, el reconocimiento de la belleza sin par de Dulcinea, aunque a su lado siempre van a estar el triste Alonso Quijano que verá desaparecer los objetos de su felicidad, los libros con biblioteca y todo, junto a la criadora de cerdos, Aldonza Lorenzo.

Otras duplas las conforman Don Quijote y Rocinante, Sancho y el asno; el cura y el barbero, los amigos de Alonso Quijano y enemigos de Don Quijote. De igual modo, andan juntos la realidad y la ficción, la cordura y la locura; el hambre y la avaricia, ya mencionadas; el amor y el desengaño; la gula y la compostura; el decoro y el desenfado; la dama y la ramera; la venta

\section{Lenguajes}

y el castillo; la razón y la sinrazón. Además, las parejas cambian de compañero como en la danza: Don Quijote y Dulcinea-Don Quijote y Mari Tornes, que recibe del caballero la más bella declaración que pueda desear una mujer al final de la primera parte cuya publicación se conmemora en este 2005.

Entre todos, constituyen la multitud de personajes $(\mathbb{F} \mathrm{n}$ que Cervantes introduce el moderno género novela 
destinado después suyo a la militancia de las letras en un mundo en el cual dominan la injusticia y la pobreza.

\section{BIBLIOGRAFÍA}

BARRIGA CASALINI, Guillermo, Los dos mundos del Quijote. Realidad y ficción, Madrid, Ediciones José Porrúa Turanzas S.A., 1983.

BARTHES, Roland, "La retórica antigua" en: La aventura semiológica, Barcelona, Piados, 1993.

CERVANTES, Miguel de, Don Quijote de la Mancha,. Edición del IV Centenario, Real Academia Española, Asociación de Academias de la Lengua Española, Madrid, Alfaguara, 2005.

DE RIQUER, Martín, Aproximación al Quijote, Madrid, Salvat, 1970, pág. 41.

EL TIEMPO, "Cervantes y el Quijote", en: Lecturas dominicales, Bogotá, 20 de abril de 2005.

FUENTES, Carlos, "Elogio de la incertidumbre", en: Lecturas dominicales, El Tiempo, Bogotá, 7 de mayo de 2005.

GARCÍA MÁRQUEZ, Gabriel, Vivir para contarla, Bogotá, Norma, 2002.

JITRIK, Noé, "Cuatro siglos de fascinación" en: Lectura Dominicales, El Tiempo, Bogotá, sábado 23 de abril de 2005.

LARA ZABALA, Hernán, "El capítulo milagroso" en: Lecturas Dominicales, El Tiempo, Bogotá, sábado 23 de abril de 2005.

MANGUEL, Alberto, Una historia de la lectura, Bogotá, 